Original Research Paper

\title{
Analysis of Steel Track Undercarriage Wear Based on Geographic Location
}

\author{
${ }^{1}$ Frederick A. Rich and ${ }^{2}$ Christopher Kluse \\ ${ }^{I}$ College of Technology, Indiana State University, Terre Haute, Indiana, USA \\ ${ }^{2}$ College of Technology, Architecture and Applied Engineering, Bowling Green, Ohio, USA
}

\author{
Article history \\ Received: 18-01-2018 \\ Revised: 3-03-2018 \\ Accepted: 26-03-2018 \\ Corresponding Author: \\ Frederick A. Rich \\ College of Technology, Indiana \\ State University, Terre Haute, \\ Indiana, USA \\ Email: frich@sycamores.indstate.edu
}

\begin{abstract}
Undercarriage management is a critical concern for heavy equipment owners that often can account for over half of the operating cost of a piece of machinery. Understanding the most economical time to stop a machine for undercarriage maintenance is critical in the management of the undercarriage system and for optimizing profitability for the equipment owner. There has been much laboratory research performed on steel track undercarriage system wear found on dozers and track type loaders, however there has been little formal research to determine the wear patterns based on geographic location. This research analyzed the entire population of track type heavy construction equipment within a construction equipment territory to determine if there are differences in the undercarriage wear rates based on geographic location. There are 5 sub-territories that are researched to determine if the wear rates are different between these 5 geographic locations. Two of these locations are in the coastal plains region of North Carolina and three are in what is known as piedmont area of the state. This research is important because the results will assist the machine owner in maximizing the life of the undercarriage system and will result in better machine maintenance recommendations for the equipment owners. The researchers tested two hypotheses, these are: (a) the median wear out rates are the same between all geographic store locations and, (b) the median wear out rate is the same between the regions. Both null hypotheses in this study were rejected indicating there are differences in the undercarriage wear rates.
\end{abstract}

Keywords: Steel Track, STM, Loader, Dozer, Excavator, Sprocket, Wear, Component

\section{Introduction}

An undercarriage on a track piece of heavy equipment transfers power from the drive train to the ground which both propels the machine and applies force to the ground engaging tools in the dirt doing the work. Undercarriage replacement costs account for up to $50 \%$ of the typical track machine operating cost and can greatly impact profitability and return on investment (ROI) to the machine owner. Knowing the optimum service meter reading to replace these wear items will increase the return on investment to the machine owner and will reduce the waste of unused sacrificial wear part life. It is suspected that this maintenance interval varies dramatically depending on the differences in geographical locations due to the different input factors and conditions the machine is primarily working in. The territory in this research has very different geological factors, topography and market segments depending on the geographic location. which all impact undercarriage life (Sessions, Leshchinsky, Chang, Boston, and Wimer, 2017). Figure 1 denotes the layout of the study area and the different locations of the stores.

Currently there is no consideration of territory location in the determination of track type tractor undercarriage replacement hours. There is a need to determine if significant variability exists in undercarriage systems maintenance intervals depending on geographic locations of where the machine is domiciled. 


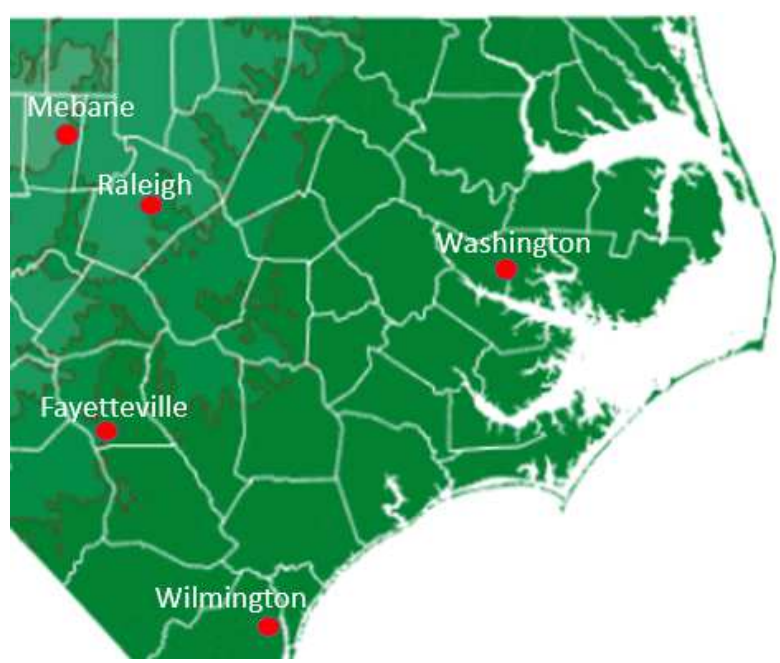

Fig. 1: Territory/store locations

Knowing this information can help machine owners make better and more timely machine maintenance decisions.

Hypothesis one determines if there is any difference in the median wear life of the undercarriage systems based on store location.

\section{Hypotheses 1}

$H_{o}$ : Median Wear Life Raleigh $=$ Median Wear Life Wilmington $_{\text {W }}$ $=$ Median Wear Life Washington $=$ Median Wear Life $_{\text {Mebane }}=$ Median Wear Life Fayetteville

$H_{A}$ : At least one Median Wear Life is Not Equal.

The territory in this analysis has two distinct ecosystems containing different topography and geology. One region is the piedmont which consists of the Mebane, Fayetteville and Raleigh store locations. The other region is the coastal plains consisting of Washington and Wilmington Fig. 3. The stores are grouped into these two categories to determine if there is difference between the median undercarriage wear life.

\section{Hypotheses 2}

$H_{o}$ : Median Wear Lift ${ }_{\text {Coastal }}=$ Median Wear Life Piedmont $H_{A}$ : Median Wear Lift ${ }_{\text {Coastal }} \neq$ Median Wear Life Piedmont

This research determined if there are statistical differences in the median undercarriage wear life on steel track machines (STM) between the Piedmont and Coastal regions.

\section{Literature Review}

There is a vast body of research performed in the specific area of undercarriage wear by civil engineering academics, equipment management practitioners and original equipment manufacturers. The extremely high cost of this type of maintenance seems to be the motivation for conducting this research. Most of the researchers agree that many of the input factors that predict undercarriage wear rates are controllable and thus researchers are looking for ways to optimize these factors in order to achieve higher profitability. Identifying these factors and understanding how they impact machine undercarriage wear is critical in the education process of the machine owner, operator and the service organizations that support the owner. The key is to help the stakeholders know how to manipulate these input factors to reduce cost of operating the machinery for long term profitability and ROI of the machine. There are three types of equipment maintenance costs and these are (a) acquisition, (b) operational maintenance and (c) residual cost and each are impacted by the input factors (Tsimberdonis and Murphree, 1994).

Operational maintenance cost has the largest financial impact and is the one that is very controllable (Tsimerdonis and Murphree, 1994). Support in the management of this maintenance cost is crucial as new equipment becomes more sophisticated and technically advanced. To maintain the high performance of the machine, proper and timely maintenance is required (Schexnayder and David, 2002). It is also found that properly maintained machines hold their value better and can expect higher residual value at the end of the machine's useful life (Lucko, Anderson-Cook \& Vorster, 2006). To be profitable in managing an equipment fleet it is critical to accurately forecast the cost of replacement wear materials and to schedule the downtime rather than repairing after failure (Mitchell et al., 2011). Knowing when to schedule steel track machine (STM) downtime before undercarriage failure occurs will aid in the positive ROI for the machine owner. Sandy soil types are 2 to 5 times harder than the ground engaging tools on the machines therefore are very abrasive (Gharahbagh et al., 2013). Wear rates of certain maintenance wear parts are directly related to the abraisivity of the soil. Based on the abrasiveness of the soil types in which the machine is working, the maintenance timing can be predicted (Lee et al., 2014). It was found that working in abrasive materials can reduce steel undercarriage life from 14,000 hours to 3,000 and the abrasiveness impacts not only tracks but other areas of the machine (Elverman, 2004). Adding moisture to the abrasive sand types has a "significant impact" to the abrasivity impacting the wear components (Gharahbagh et al., 2014). Other input factors could include topography, machine operator techniques and the type of work being performed. Many of these input factors can be different as one moves from one geographic location to another.

\section{Materials and Methods}

It is important to know where on the machine the undercarriage system is located to help the reader visualize the area. The red arrow in Fig. 2 identifies the area where the critical wear point location for which this paper is concerned. 


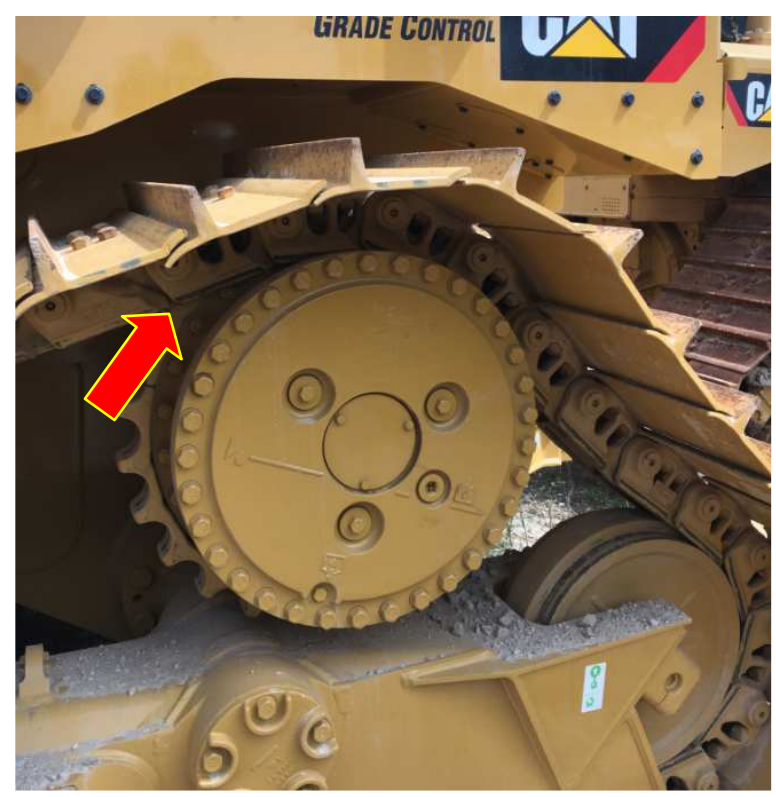

Fig. 2: Critical steel track wear point of a Track Type Dozer

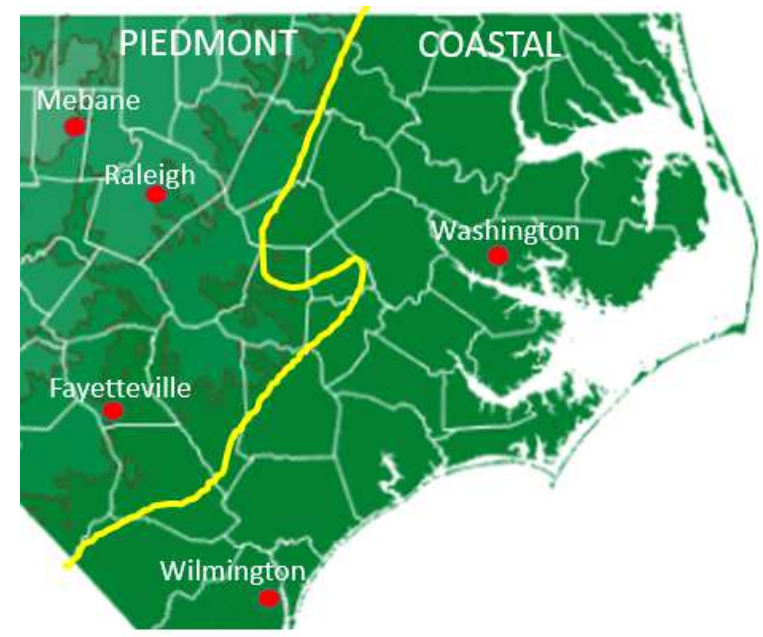

Fig. 3: Coastal and Piedmont Regions of Eastern North Carolina

Table 1: Layout of Undercarriage Replacement Data

\begin{tabular}{llll}
\hline Data Set Layout & & \\
\hline Store & Region & County & SMU \\
\hline Categorical & Categorical & Categorical & Interval \\
Fayetteville & Piedmont & Cumberland & 2259 \\
Wilmington & Coastal & New Hanover & 2101 \\
Raleigh & Piedmont & Wake & 3389 \\
Washington & Coastal & Beaufort & 2157 \\
\hline
\end{tabular}

This study focused on a heavy equipment population in eastern North Carolina which is comprised of five subterritories located strategically throughout their area shown in Fig. 3. Two of these subterritories are located on the coastal area while three are much farther inland in the piedmont area.

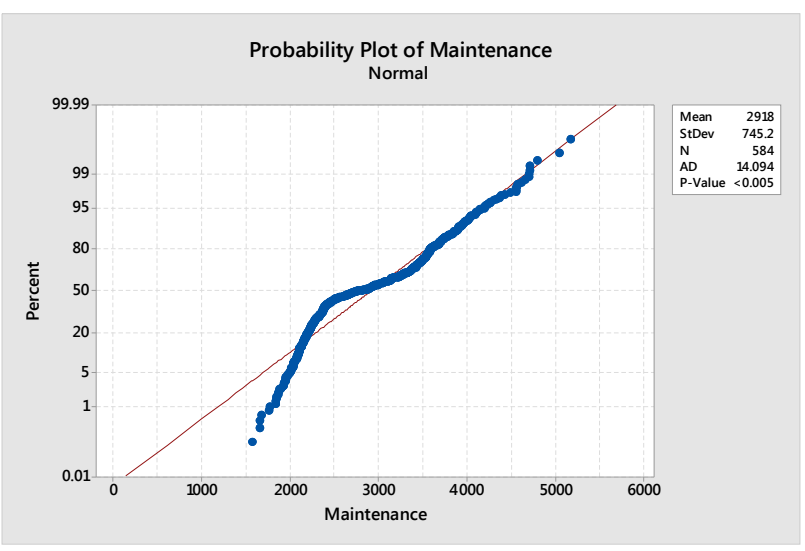

Fig. 4: Probability Plot and Normality Test of SMU Data Results

Data is required to be gathered from the population of STM's in this territory footprint regarding the historical life of the undercarriage systems. The research began with the extraction of a total population of ex post facto data of undercarriage purchased through the five service shop locations for the years of 2016 and 2017. Acquiring the data from the service shops is critical because service calls always captures the Service Meter Unit (SMU) reading or hour meter reading which is the "Y" dependent variable in this research. This reflects the total number of hours the machine has been operated. Table 1 provides the layout of this data set with four lines of data as examples. Row one simply is the title row. Row two identifies the variable type and denotes if the variable is dependent or independent. Row three identifies the data type while the last four rows are actual data.

Column 2 references the SMU hours mentioned above. The store field is the store location where the service call was opened and the undercarriage was sold. An assumption is made that if the machine was repaired at a particular store then the machine would work primarily in the store's geographic area. There can always be some overlap as jobs may carry a local contractor outside the store's sub-territory. The region column in Table 1 is graphically shown in Fig. 4 and are designated either piedmont in orange or coastal in yellow.

The data population consists of 584 data points which represents every machine repaired where the part numbers for the steel track were sold on a service call in 2016 and 2017. After the data was extracted, there were some data point outliers removed. If tracks were replaced at less than 100 SMU hours, this would typically represent a machine sell where the equipment owner requested a different type of track configuration. An area where data bias could enter this study is where the machine undercarriage is replaced either too early or too late in the maintenance cycle. Replacing too early will waste unused undercarriage resource and replacing too 
late can damage the structural frameworks and power train components of the machine. There is no way to determine if the optimum maintenance SMU after the fact therefore, the researchers assumed that replacements are performed at the proper maintenance interval.

\section{Results}

A normality test was performed and it is found that the data is non-normal as shown in Fig. 5. The p-value is less than 0.05 therefore the null hypothesis which states the data set is normal must be rejected. Working with non-normal data requires the use of nonparametric statistical tests to prove the null hypothesis (Pyzdek and Keller, 2014). In this case, the store location and region is the two significant categorical input factors that will be used in the Moods Median Test with the SMU being the dependent variable.
Figure 5 presents a compilation of all 584 data points in this study. The mean hours for track replacement is 2,918 hours of operation with a wide standard deviation of 745 hours. The minimum SMU is 1,574 hours and the maximum life experiences 5,165 hours. The data appears to be bimodal and the mean and median are quite large number of values apart which is another sign of the presence of non-normal data.

Table 2 reflects the decomposition of the graphical summary in Fig. 6. This statistical summary of the SMU readings shows that the lowest mean store value at 2226 hours is at the Wilmington store and the greatest wear life on average is 3380 hours at the Mebane location. It is important to note the range of the standard deviations which vary from a minimum of 252 to 738 hours between stores.

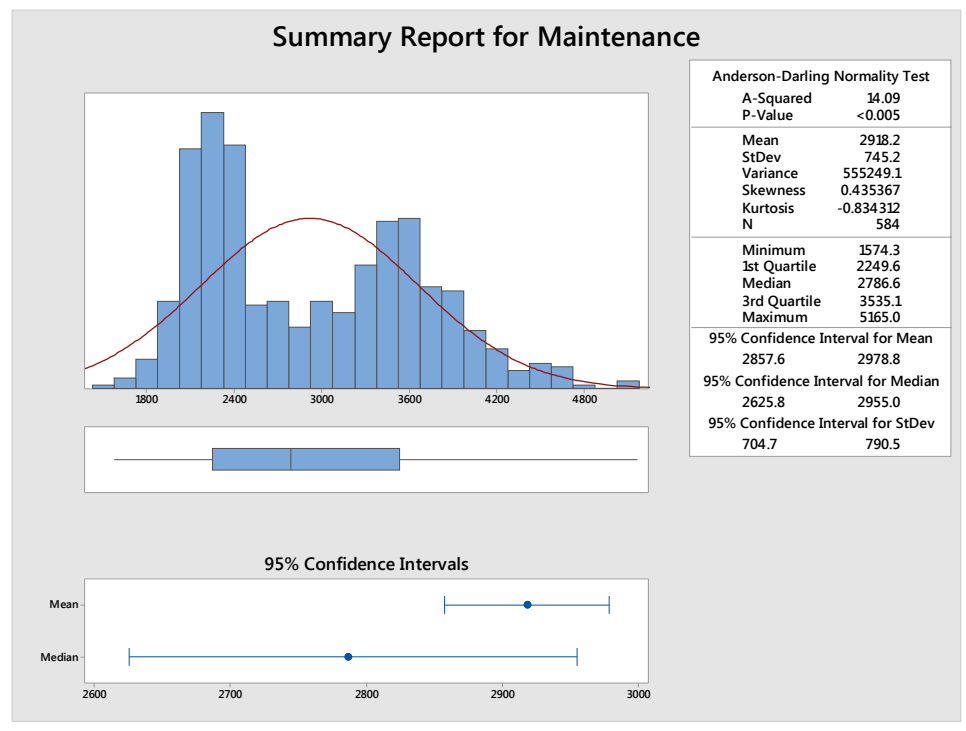

Fig. 5: Cumulative Graphical Summary of All SMU Readings

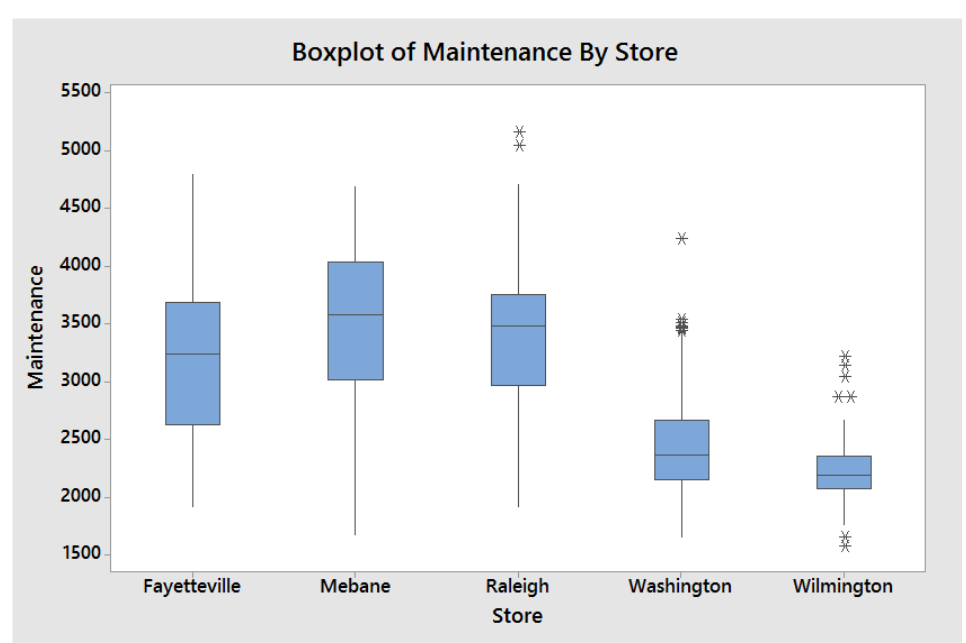

Fig. 6: Box Plot of Steel Track Replacement Hours by Store Location 
Table 2: Statistical Summary of SMU Readings by Store Location

\begin{tabular}{llllll}
\hline & Data Set Statistical Summary Table & \\
& -- & Mean & StDev & Min & Max \\
\hline Fayetteville & 73 & 3228 & 698 & 1922 & 4798 \\
Mebane & 30 & 3408 & 738 & 1679 & 4696 \\
Raleigh & 228 & 3380 & 615 & 1914 & 5165 \\
Washington & 116 & 2485 & 470 & 1653 & 4239 \\
Wilmington & 137 & 2226 & 252 & 1574 & 3213 \\
\hline
\end{tabular}

Table 3: Tukey Test of Groupings of SMU by Store

Tukey Pairwise Comparisons

Grouped with 95\% Confidence

\begin{tabular}{llll}
\hline Store & $\mathrm{N}$ & Mean & Grouping \\
\hline Mebane & 30 & 3408 & $\mathrm{~A}$ \\
Raleigh & 228 & 3380 & $\mathrm{~A}$ \\
Fayetteville & 73 & 3228 & $\mathrm{~A}$ \\
Washington & 116 & 2485 & $\mathrm{~B}$ \\
Wilmington & 137 & 2226 & $\mathrm{C}$ \\
\multicolumn{4}{l}{ Means that do not share a letter are significantly different }
\end{tabular}

It is indicated by the box and dot plots in Fig. 6 that the Wilmington and Washington stores having lower wear replacement mean hours compared to the other three stores.

Additionally, a Tukey Pairwise comparison was performed to determine if the confidence intervals of the mean overlap and this analysis is shown in Table 3. If there is overlap in the confidence intervals the stores will be placed in a separate grouping. In this case the Mebane, Raleigh and Fayetteville locations all belong to group A reflecting the possibility that the confidence intervals could overlap indicating the mean could be common in both locations. Wilmington and Washington are both different showing no overlap with any other store and are assigned a B and C grouping respectively.

Figure 7 provides additional evidence showing that the confident intervals do not share any confidence interval values between groupings A, B or C. This indicates there is something different between these three grouping of stores causing the undercarriage maintenance SMU interval differences.

The result of the Mood Median Test for the nonnormal data is reflected in Table 4. The test result shows a p-value of 0.000 indicating all the stores median values are the same. Looking at the confidence intervals it again appears that the Washington and Wilmington stores have a substantially lower median value than the three other stores in the analysis. There are also visible differences between Washington and Wilmington reinforcing the Tukey grouping results showing the overlap of the confidence intervals between the $\mathrm{A}, \mathrm{B}$ and $\mathrm{C}$ groupings.
Table 4: Mood Median Test Results for SMU Reading by Store

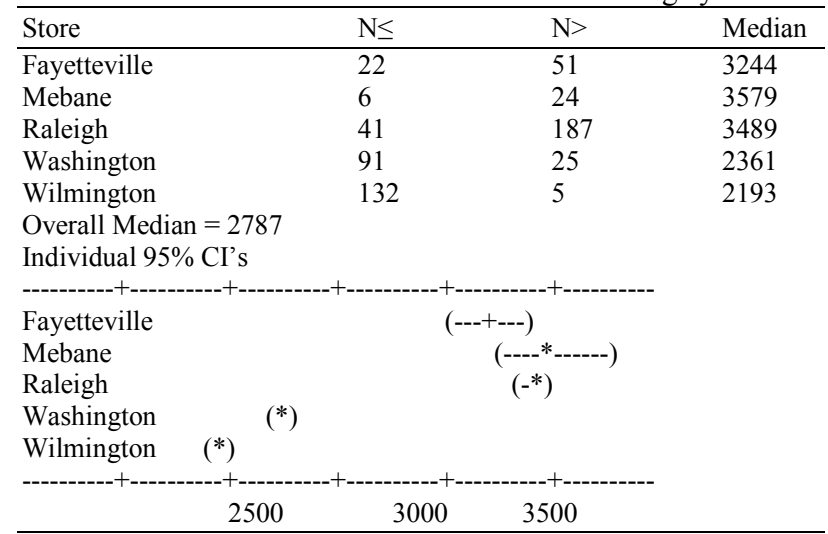

Mood Median Test: Maintenance versus Store

Mood median test for maintenance

Chi-Square $=271.09$

Table 5: Tukey Pairwise Comparison of SMU by Region Tukey Pairwise Comparison Groupings are at $95 \%$ Confidence

\begin{tabular}{llll} 
Region & N & Mean & Grouping \\
\hline Piedmont & 276 & 3580 & A \\
Coastal & 308 & 2324 & B \\
\hline
\end{tabular}

Means that do not share the same letter are significantly different

Table 6: Mood Median Test of Steel Track Replacement Hours by Region

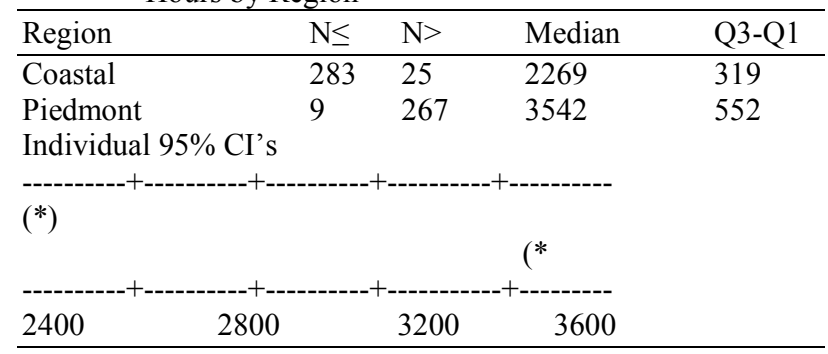

Mood Median Test: Maintenance vs Region

Mood Median test for Maintenance

Chi-Square $=457.29$

$\mathrm{DF}=1, \mathrm{P}=0.000$

To determine possibly another factor that differentiates the wear life, the store populations were consolidated into two new larger populations of coastal and piedmont. From Figure 8 one can see quite a difference between the two data sets in the histogram.

A Tukey Pairwise comparison was again performed to determine if the confidence intervals of the mean overlap. If there is overlap in the confidence intervals the regions will have a separate grouping. In this comparison shown in Table 5, the regions are different for the piedmont region is assigned to group A and the coastal region to group B.

Figure 9 shows the differences between these two populations while Fig. 10 shows that the confident intervals do not contain the mean value between groupings $\mathrm{A}$ or $\mathrm{B}$. 
This indicates there is something different between these two regional groupings causing differences in the undercarriage maintenance SMU intervals.

Table 6 are the Moods Median Test containing the two regions as the independent categorical variable. One can see the p-value is again 0.000 therefore, statistical significance is present and the null hypothesis is rejected. There is quite a difference between the wear out rates of the steel tracks depending on which subterritory one operates their STM.

The data shows a bimodal characteristic and if one was to add the categorical factor of region to this data set the bimodal characteristic seems to be explained by the different regions shown in Fig. 9. The blue histogram shows the distribution of repair SMU readings for the tractors in the coastal region and the red histogram denotes the machines in the piedmont region with SMU hours on the horizontal axis.

It has been demonstrated that there are differences in the average replacement hours of undercarriage systems on STM between both store locations therefore, the first null hypothesis should be rejected and the alternate accepted. It has also been demonstrated there are differences in the average replacement hours of undercarriage systems by region and, the second null hypothesis is rejected as well and the alternate accepted.

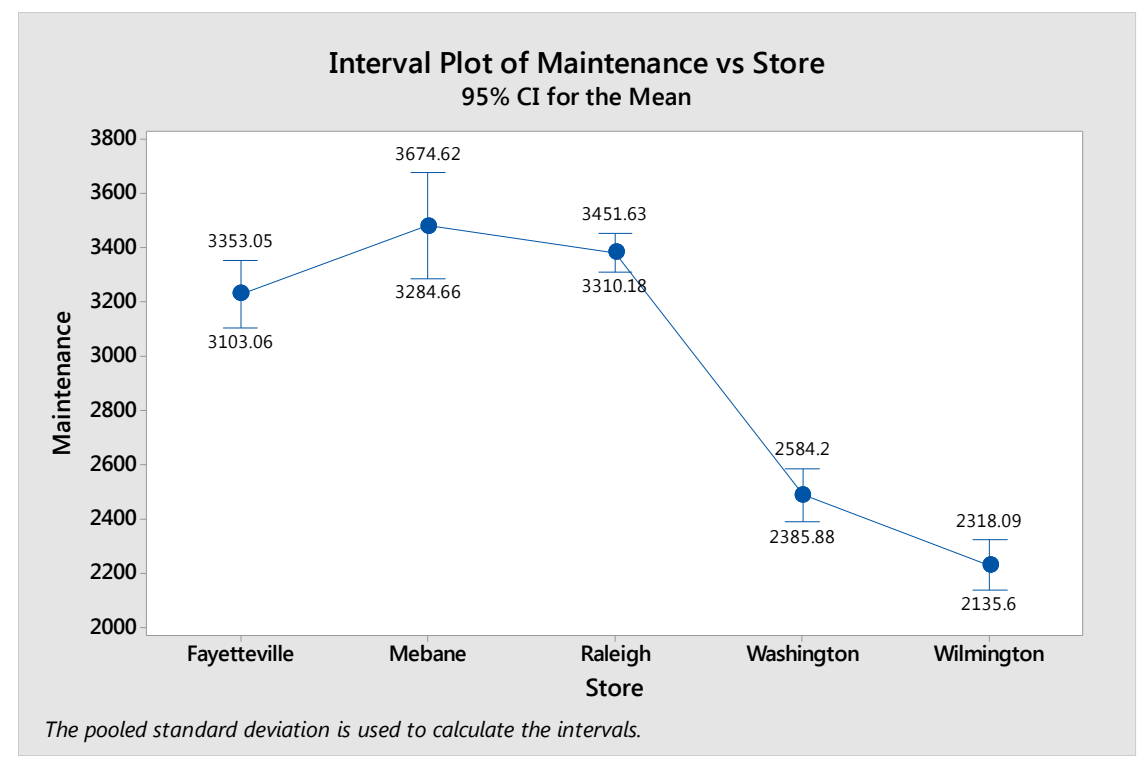

Fig. 7: Tukey Pairwise Comparison Mean Confidence Interval Plots

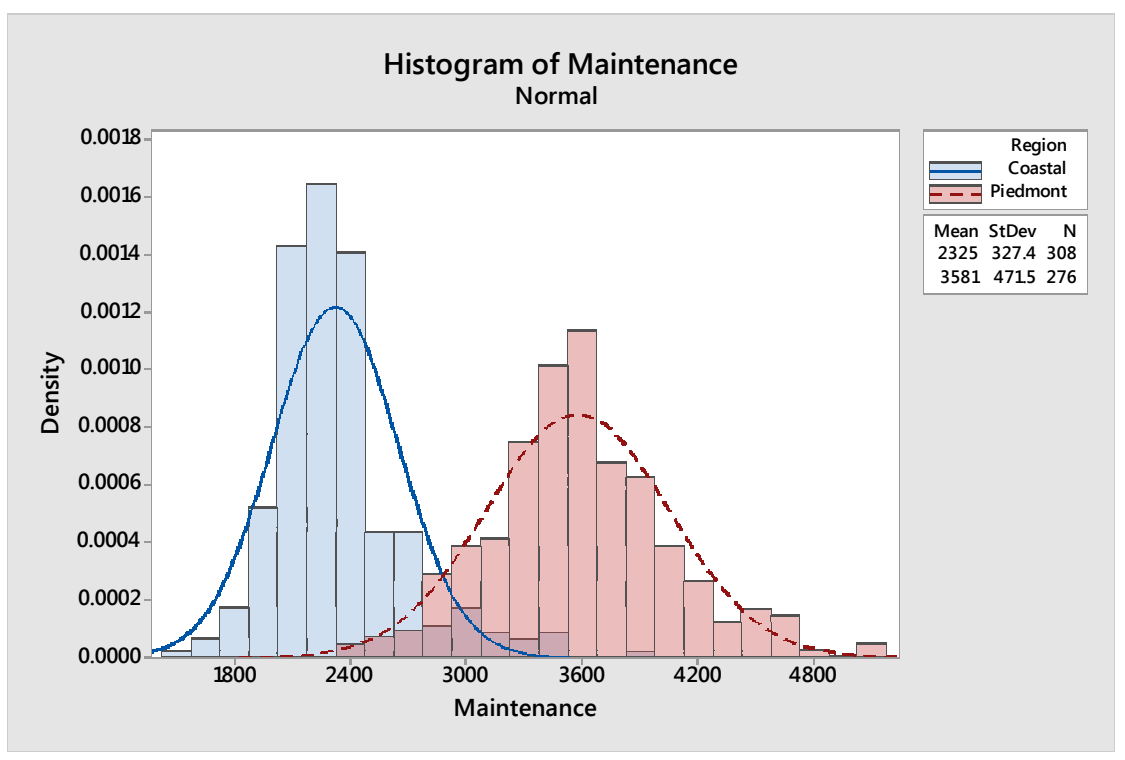

Fig. 8: Initial Bimodal Statistical Summary by Regions 


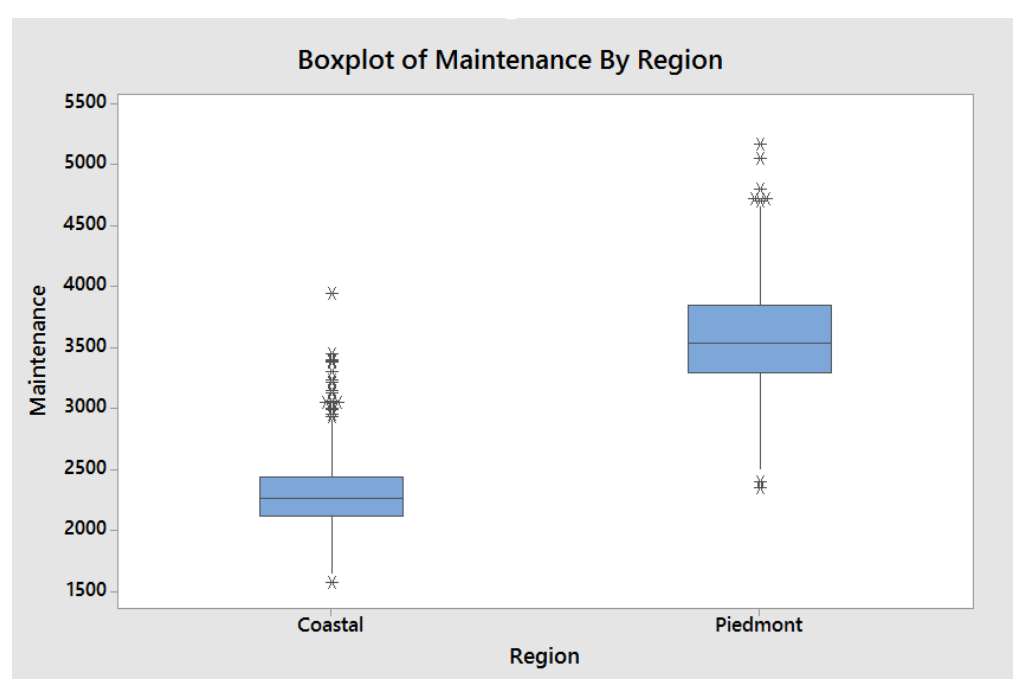

Fig. 9: Box Plot of Coastal and Piedmont Replacement Hours

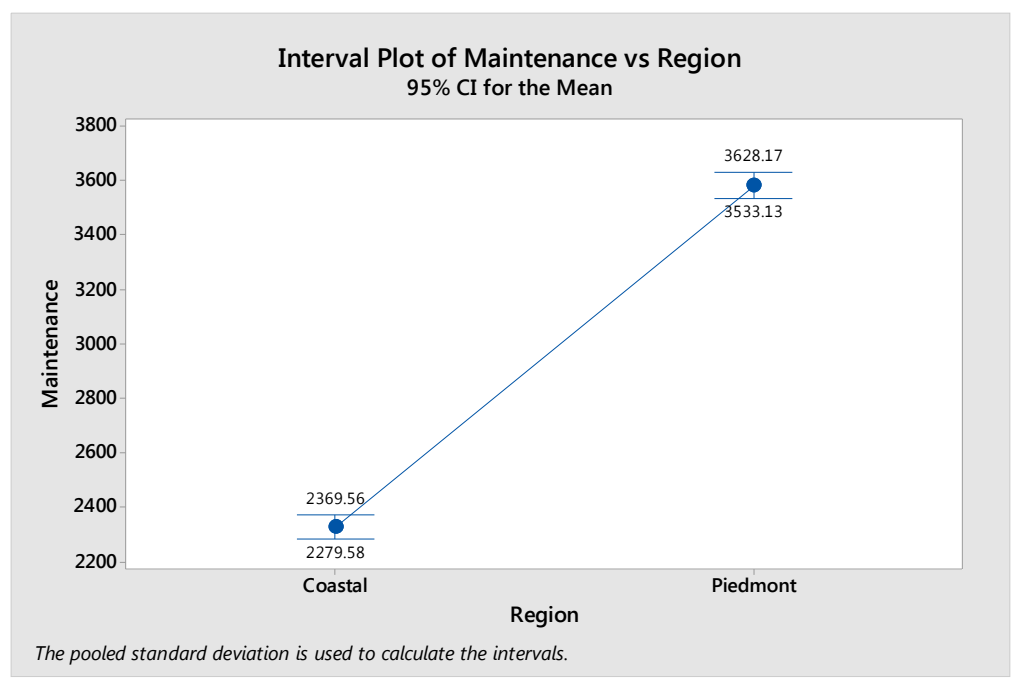

Fig. 10: Interval Plot of Maintenance SMU by Region

\section{Discussion}

This new information can be leveraged to provide improved support of the undercarriage system for the equipment owners to ensure they get the optimal life out of their undercarriage investment. This information can also be leveraged to better market repair parts and service to the machine owners. By knowing that the average steel track replacement hours are far less in the coastal region and by store, the marketers can tailor sales plans to be timelier and nearer to the actual time of replacement. It would be ideal to contact the equipment owner at the minus 1 standard deviation SMU noted in the Mean-One STD column of Table 7. For example, Mebane based equipment owners should be notified at about 2,742 hours while in Wilmington the trigger should be in the 1974 hour range.
Table 7: Projected SMU to Undercarriage Maintenance

\begin{tabular}{llll}
\hline & Projected First Call & \\
Store & - Std. Dev. & Mean & Mean-1 Std Dev \\
\hline Mebane & 738 & 3480 & 2742 \\
Raleigh & 615 & 3380 & 2765 \\
Fayetteville & 699 & 3228 & 2529 \\
Wilmington & 252 & 2226 & 1974 \\
Washington & 470 & 2485 & 2015 \\
\hline
\end{tabular}

If the same SMU hour strategy is used in Wilmington as in Mebane, the equipment owner in Wilmington could have already have purchased tracks before the salesman would have the opportunity to call on this equipment owner. This is key information to have and leverage to help the equipment owner be more effective and efficient. Performing this analysis periodically can help 
market the replacement parts more effectively. Knowing when to call on the machine owner prior to a need is critical in providing superior service recommendations on the hours shown in Table 7. A more serious situation results when the equipment owner destroys the rollers and idler assemblies by running the undercarriage system past the destruction point which will drive much more cost to the equipment owner. If the machine continues to be ran other serious structural failure of the track roller frame could occur or worse yet power train failure of the final drive. Machine owners can use this information to better prevent these catastrophic failures from occurring occurring (Hawkins and Dewitt, 2013).

There could be many causes for these differences but the geology differences between the regions across the territory could be plausible and significant reasons for these differences requiring more investigation. Other causations such as operator techniques, type of work performed or the tightness of the track adjustment that will account for the other variation and all could be investigations for further research. This same analysis could be performed in another and different geographic region to validate the results. Given the low $p$ values seen in this study, it stands to reason the correlation should be found in other territories.

It would be particularly interesting if this study could also be performed in a territory that has similar topographic and geological gradients across the territory. Another factor that was mentioned but not investigated was the impact of the wet and swampy conditions found in our coastal plain area, which in this study also correlated with the silicon based soil types. Finally, it would be interesting to understand why there are such differences in the standard deviations in the SMU of the maintenance intervals between stores.

Using SMU data as a predictor by the specific store location will help be more granular in making sale call decisions. This can aid the equipment owner in maximizing the investment made when the machine was purchased. The goal is to know the optimum SMU for the equipment owner to stop the machine for maintenance. This knowledge will help provide better service and will help build positive relationships with the equipment owners helping them maximize undercarriage life that could extend the useful life of the investment.

\section{Conclusion}

It can be concluded that there are differences in median undercarriage life depending on the geographic location of the machine. It was observed that these differences occurred by geographic store location and by geographic region. Undercarriage life was far shorter along the coastal plain region where there are higher moisture levels and more abraisivity in the soils. This supports the studies done by lee, Kim and Youn which found wear rates are directly related to the abrasivity of the soil (Lee et al., 2014). This also supports the study done by Gharahbagh, Qiu and Rostami that adding moisture has significant impact to machine component wear rates (Gharahbagh et al., 2014). Further research could be initiated to further substantiate the cause and effect of these input factors and to further understand why there are differences in median undercarriage wear rates between territory store location and geological region.

\section{Acknowledgment}

This research was performed with no funding from any outside sources.

\section{Author Contribution}

Frederick A. Rich: This research was completed as a project requirement for the course QS7270 Document Based Process Improvement taken at Bowling Green State University. Frederick Rich was the student and Dr. Christopher John Kluse was the professor. Frederick Rich collected the data, performed the analysis and completed the document.

Dr. Christopher Kluse: Reviewed the scope, methods and data analysis while providing feedback on content and manuscript organization. The final document was reviewed and revised by both authors to ensure content correctness and formatting for publication.

\section{Ethics}

This document is an original work and has not been published or considered for publication in any other journal. Reference has been given to the appropriate contributors. Both the corresponding and contributing authors have read and approved this work.

\section{References}

Elverman, B., 2004. True grit: Oil sands dozers battle sand and weather. Equipment Maintenance J., 205: 26-29.

Gharahbagh, E., T. Qiu and J. Rostami, 2013. Evaluation of granular soil abrasivity for wear on cutting tools in excavation and tunneling equipment. J. Geotech. Geoenviron. Eng., 139: 1718-1726.

DOI: 10.1061/(ASCE)GT.1943-5606.0000897

Gharahbagh, E., T. Qiu and J. Rostami, 2014. Effect of water content on the abrasivity of granular soils in soft ground tunneling applications. Geo-Congress 2014 Technical Papers, GSP 234.

Hawkins, B.E. and C.N. Dewitt, 2013. Wear Monitoring Device and Method of Monitoring Undercarriage and Roller Wear. US Patent Application Publication. 13/835,626, 
Lee, T., G. Kim and H. Youn, 2014. Development of rotary abrasion testing apparatus for rock cores. Proceedings of the Rock Mechanics and Its Application in Civil, Mining and Petroleum Engineering, May 26-28, Shanghai, China. DOI: $10.1061 / 9780784413395.006$

Lucko, G., C. Anderson-Cook and M. Vorster, 2006. Statistical considerations for predicting residual value of heavy equipment. J. Constr. Eng. Manage., 132: 723-732.

DOI: 10.1061/(ASCE)0733-9364(2006)132:7(723)

Mitchell, Z., J. Hildreth and M. Vorster, 2011. Using the cumulative cost model to forecast equipment repair costs: Two different methodologies. J. Constr. Eng. Manage., 137: 817-822.

DOI: 10.1061/(ASCE)CO.1943-7862.0000302

Pyzdek, T. and P. Keller, 2014. Six Sigma Handbook: A complete Guide for Green Belts, Black Belts and Managers at All Levels. 1st Edn., McGraw Hill, New York, New York.
Schexnayder, C. and S. David, 2002. Past and future of construction equipment Part 4. J. Constr. Eng. Manage., 128: 279-286.

DOI: 10.1061/(ASCE)0733-9364(2002)128:4(279)

Sessions, J., B. Leshchinsky, W. Chung, K. Boston and J. Wimer, 2017. Theoretical stability and traction of steep slope tethered feller bunchers. Forest Sci., 63: 192-200.

Tsimberdonis, A. and E. Murphree, 1994. Equipment management through operational failure costs. J. Constr. Eng. Manage., 120: 522-535.

DOI: 10.1061/(ASCE)0733-9364(1994)120:3(522) 